\title{
Down syndrome with asymptomatic neuroglial cyst: A case report and review of the literature
}

\author{
Seung Do Yang', Seung Ju Lee ${ }^{2}$, Dong Hwan Lee ${ }^{3}$, and Yong Hee Hong, ${ }^{1}$ * \\ ${ }^{1}$ Department of Pediatrics, Soonchunhyang University Bucheon Hospital, Soonchunhyang University College of Medicine, Bucheon, Korea \\ ${ }^{2}$ Department of Pediatrics, Soonchunhyang University Cheonan Hospital, Soonchunhyang University College of Medicine, Cheonan, Korea \\ ${ }^{3}$ Department of Pediatrics, Soonchunhyang University Seoul Hospital, Soonchunhyang University College of Medicine, Seoul, Korea
}

Down syndrome (DS, trisomy 21) is associated with neuroanatomical abnormalities, including choroid plexus cysts and various types of brain tumors. Trisomy 21 is associated with oncogenic factor, especially in brain tumor. The brain of DS patients had a smaller volume of gray and white matter and an unbalanced cerebellum volume, indicating a smaller volume overall than normal. We report a case of a DS male patient who had an incidentally discovered neuroglial cyst in left cerebellar vermis. He visited our hospital with gait disturbance and fatigue. But, the neurologic exam was normal. To the best of our knowledge, this is the first reported case of a neuroglial cyst in a trisomy 21 patient. As the developmental mechanisms of a cyst and the choroid plexus are related, more research is needed.

Key words: Central nervous system cysts, Cysts, Down syndrome, Neuroglia.

\section{Introduction}

The central nervous system (CNS) abnormalities related to Down syndrome (DS) occur because of a complex combination of abnormal development and functional change, directly caused by overexpression of the genes responsible for the production of trisomic cells [1]. Almost all patients with DS have some form of intellectual disability (ID), and DS is the most common genetic cause of ID. Other symptoms of DS include cardiac malformations, gastrointestinal anomalies, and skeletal anomalies [2]. Patients with DS can develop various types of tumors, and several choroid plexus cysts have been reported [3]. Such cysts are sonographically evident in about $1 \%$ of all secondtrimester fetuses with DS [4].

Brain tumors are frequently reported in individuals with DS
[5]. Tumors involving the CNS account for 20\% of the tumors in children with DS, and these patients have a specific tumor profile, with certain tissues associated with malignant diseases. It would seem that, overall, in patients with DS, certain tissues are especially vulnerable to tumors, whereas other patients seem to have an additional degree of resistance to oncogenesis. In particular, trisomy 21 may favor tumorigenesis of hematopoietic and germ cells in children and young adults [5]. However, to the best of our knowledge, a neuroglial cyst, which is a rare and benign brain tumor, has not been reported in patients with DS. Here, we review the literature on brain tumors in patients with DS and report a case in which a neuroglial cyst was evident on brain magnetic resonance imaging (MRI) in a patient with DS.

\footnotetext{
Received: 13 June 2017, Revised: 5 September 2017, Accepted: 9 September 2017, Published: 31 December 2017

*Corresponding author: Yong Hee Hong, M.D.

Department of Pediatrics, Soonchunhyang University Bucheon Hospital, 170 Jomaru-ro, Bucheon 14584, Korea.

Tel: +82-32-621-6723, Fax: +82-32-621-5018, E-mail: dr4baby@naver.com

Conflict of interest: The authors declare that they do not have any conflicts of interest.

(c) This is an open-access article distributed under the terms of the Creative Commons Attribution Non-Commercial License (http://creativecommons.org/licenses/by-nc/4.0/) which permits unrestricted non-commercial use, distribution, and reproduction in any medium, provided the original work is properly cited.

(c) Copyright 2017 by the Korean Society of Medical Genetics and Genomics

www.e-kjgm.org
} 


\section{Case}

An 8-year-old male visited Soonchunhyang University Bucheon Hospital complaining of gait disturbance and fatigue. His medical history included birth at 32 weeks of gestation with a birth weight of $2.7 \mathrm{~kg}$ via normal spontaneous vaginal delivery; his birth followed that of two previous siblings with no evident abnormalities. He was diagnosed with DS at birth $\left(47, X Y_{1}+21\right)$ (Fig. 1), with no family history of DS. At the age of 7, the patient underwent an operation to treat a persistent patent ductus arteriosus. The patient demonstrated common physical traits associated with DS including a broad flat face, a flat nasal bridge, an upturned nose, a small arched palate, and a short neck. All of his anthropometric measurements (height, weight, and head

\section{Cytogenetics Result Report}

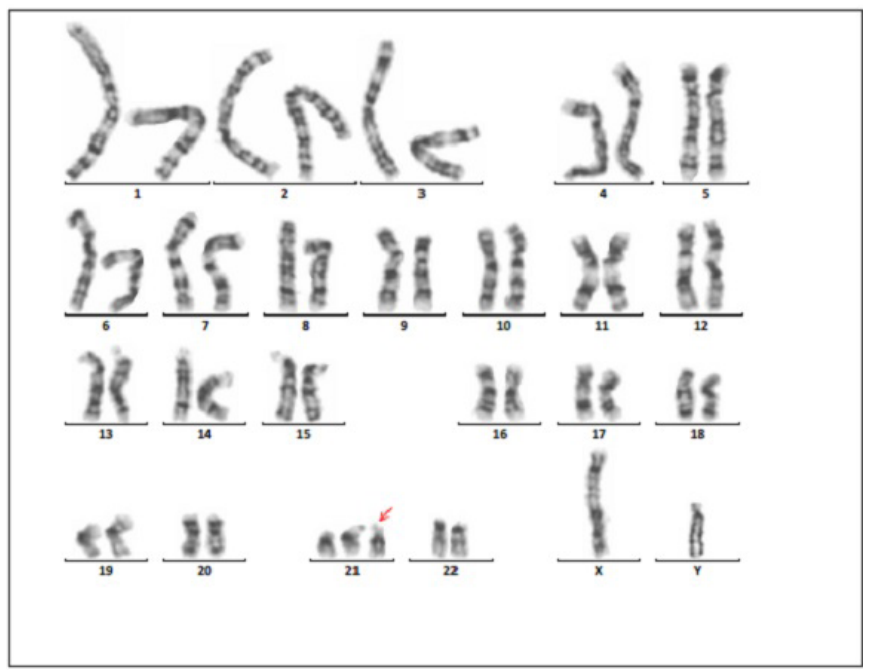

Fig. 1. Identified trisomy 21 on chromosomal analysis. circumference) were below the third percentile for age and sex, according to the Korean growth standard established in 2007 by the Korean Centers for Disease Control and Prevention [6]. Upon physical examination and interview, the patient's parents said that the child's gait was strange, but no gait disturbance was found. His mental status was alert, without dysarthria; on performing a cerebellar function test, the motor strength of his upper and lower extremities were found to be normal (5/5), as was his DTR grade (2/4). He reported normal muscle sensations. Heel-to-toe test and Romberg's test were normal. On admission, all his vital signs were normal, and his complete blood differential counts were within normal ranges, as follows: white blood cells, 6,200/ $\mu \mathrm{L}$; hemoglobin, $13.5 \mathrm{~g} / \mathrm{dL}$; hematocrit, 39\%; and platelet count $288,000 / \mu \mathrm{L}$. Moreover, his aspartate aminotransferase and alanine aminotransferase levels were within normal ranges (34/34 IU/L). No electrolyte imbalance was evident and his sodium/potassium/chloride ( $\mathrm{Na} / \mathrm{K} / \mathrm{Cl}$ ) levels were 139/4.7/104 $\mathrm{mmol} / \mathrm{L}$. A thyroid function test revealed a thyroid-stimulating hormone level of $4.0 \mu \mathrm{lU} / \mathrm{mL}$ and a free thyroxine (T4) concentration of $1.25 \mathrm{ng} / \mathrm{dL}$. Brain MRI revealed a neuroglial cyst approximately $1 \mathrm{~cm}$ in diameter in the left cerebellar vermis adjacent to the fourth ventricle. A developmental venous anomaly was evident in the left cerebellum (Fig. 2). He was discharged after observation, without any specific treatment.

\section{Discussion}

The brain of a child with DS develops differently from the brain of a neurotypical child [7]. Neurodevelopmental changes are evident in both the prenatal and early postnatal periods. Neurogenesis is disrupted and the numbers of cortical neurons

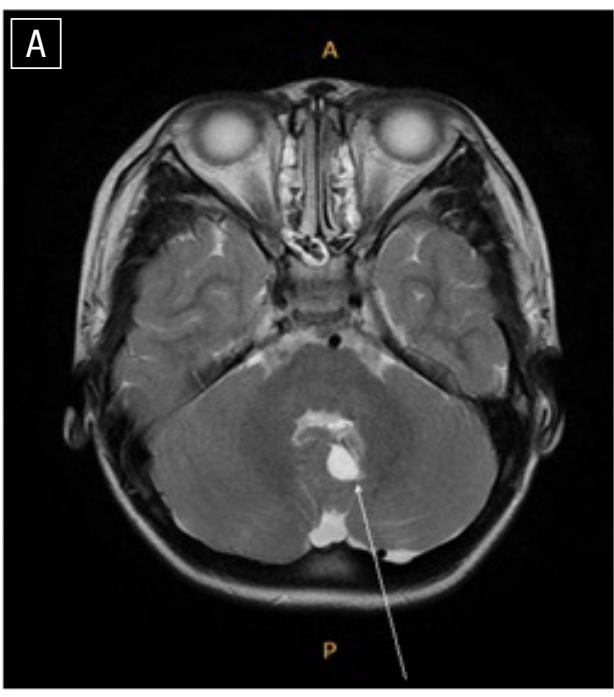

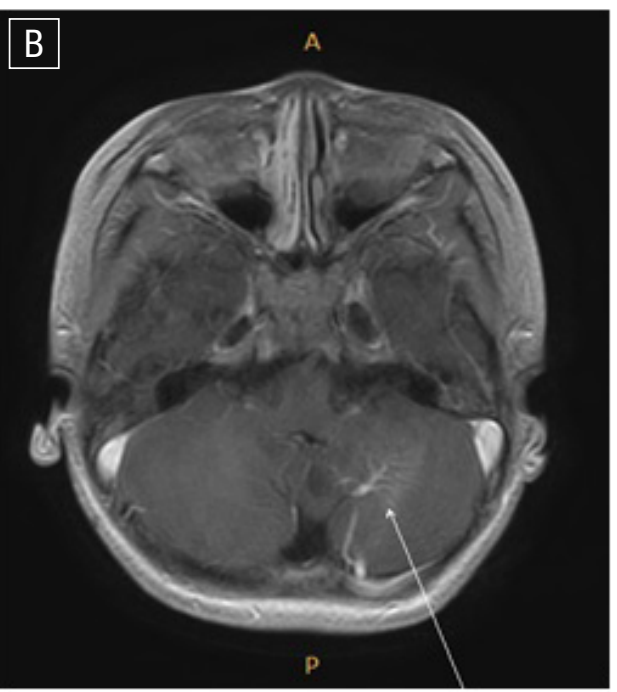

Fig. 2. (A) Neuroglial cyst (arrow) of patient's magnetic resonance image. (B) Developmental venous anomaly (arrow) in left cerebellum. 
decrease, triggering changes in myelination $[8,9]$. After about 4 months, the neurons exhibit enlarged dendrites, but these dendrites stop growing within the first year, and the neurons then appear atrophied compared with neurons in a typical brain at the same age [7]. The expression levels of various neurotrophic factors, including brain-derived neurotrophic factor (BDNF), fall during early development of the brain of patients with DS [10]. BDNF is a neurotrophin that plays a key role in neurogenesis and the maintenance of neuronal plasticity by binding specifically to tropomyosin-related kinase receptor B [11].

Brain tumors in patients with DS exhibit a specific distribution, and differ from those of the general population [12]. On autopsy, DS has been found to be associated with neuroanatomical abnormalities in the corpus callosum, ventricular hypertrophy, and malformations of the cerebellum, frontal lobe, temporal lobes, and brain stem $[13,14]$. In particular, choroid plexus cysts are associated with trisomy 21 [15]. Most studies exploring the association of choroid plexus cysts and chromosome aberrations have evaluated heterogeneous high-risk populations [16]. Such cysts are typically detected in the second trimester, presenting as sonolucent cysts associated with the lateral ventricles, demonstrating cyst diameters ranging between a few millimeters and 1-2 cm. These cysts may be echogenic because the cysts are surrounded by the choroid plexus [17].

A neuroglial cyst is a benign epithelial lesion that may develop anywhere in the neuraxis. Neuroglial cysts account for $<1 \%$ of all intracranial cysts [18] and are more common in the occipital area than in the cerebral hemisphere. Intraparenchymal cysts are more common than extraparenchymal cysts. Such cysts are also termed glioependymal cysts. Neuroglial cysts are derived from isolated embryonic neural tube elements; the cysts are round, soft, monocular, and contain a clear liquid similar to cerebrospinal fluid (CSF). The cysts are surrounded by ependymal cells or those of the choroid plexus [19]. Upon ultrasound examination, the cysts are found to resemble arachnoid cysts [20].

Neuroglial cysts vary in size and are non-enhancing, and abnormalities in the surrounding signal intensities are minimal to absent. Cranial computed tomography reveals uniformly hypodense lesions with no contrast enhancement. MRI reveals well-defined cysts that are isointense to the CSF on T1-weighted images and isointense or mildly hyperintense on both protondensity and T2-weighted images [21]. The cysts are benign and have smooth round borders.

The origin of such cysts remains controversial, although it has been hypothesized that they develop during embryogenesis via sequestration of the developing neuroectoderm [22].
Abnormally developing brain areas may be conducive to cyst formation. It has also been proposed that the cysts originate via ectopic displacement of neural tube wall segments at the site of tela choroidea formation [23]. If this is the case, a cyst would be a congenital abnormality of the ventricular process [24].

These cysts may be asymptomatic for long periods, throughout the fetal period and into adulthood. Their clinical signs are attributable to associated anomalies, including callosal dysgenesis, neuronal heterotopia, and/or cortical dysplasia, or related malformation syndromes, like orofaciodigital syndromes, especially of types I and II, and Aicardi syndrome [25]. Sometimes, the cysts trigger symptoms such as headaches or epileptic seizures. The neurological defects associated with the cysts depend on the location and size of the lesion [26]. Some pediatric cases with glioependymal cysts exhibit a loss of neurological function and intracranial hypertension, which are associated with in utero observations of abnormal brain development [27].

To the best of our knowledge, this is the first report of a neuroglial cyst in a patient with DS. As neuroglial cysts are covered with ependymal cells of the choroid plexus, further research on the development of neuroglial cysts in patients with DS is needed.

\section{Acknowledgements}

This work was supported by the Soonchunhyang University Research Fund.

\section{References}

1. Haydar TF, Reeves RH. Trisomy 21 and early brain development. Trends Neurosci 2012;35:81-91.

2. Chapman RS, Hesketh $\sqcup$. Behavioral phenotype of individuals with Down syndrome. Ment Retard Dev Disabil Res Rev 2000;6:84-95.

3. Bonsi AB, Boni RC, Ribeiro LAM, Souza MR. Choroid plexus cysts and their anatomical correlations: importance in fetal prognosis. A critical literature review. Braz J Morphol Sci 2009;26:12-3.

4. Newberger DS. Down syndrome: prenatal risk assessment and diagnosis. Am Fam Physician 2000;62:825-32, 837-8.

5. Satgé $D$, Sommelet $D$, Geneix $A$, Nishi $M$, Malet $P$, Vekemans $M$. A tumor profile in Down syndrome. Am J Med Genet 1998;78:207-16.

6. Moon JS, Lee SY, Nam CM, Choi JM, Choe BK, Seo JW, et al. 2007 Korean National Growth Charts: review of developmental process and an outlook. Korean J Pediatr 2008;51:1-25.

7. Becker L, Mito T, Takashima S, Onodera K. Growth and development of the brain in Down syndrome. Prog Clin Biol Res 1991;373:133-52. 
8. Wisniewski KE. Down syndrome children often have brain with maturation delay, retardation of growth, and cortical dysgenesis. Am J Med Genet Suppl 1990;7:274-81.

9. Ábrahám $H$, Vincze $A$, Veszprémi $B$, Kravják $A$, Gömöri É, Kovács GG, et al. Impaired myelination of the human hippocampal formation in Down syndrome. Int J Dev Neurosci 2012;30:147-58.

10. Bianchi P, Ciani E, Guidi S, Trazzi S, Felice D, Grossi G, et al. Early pharmacotherapy restores neurogenesis and cognitive performance in the Ts65Dn mouse model for Down syndrome. J Neurosci 2010;30:876979.

11. Stagni F, Emili M, Giacomini A, Guidi S, Ciani E, Bartesaghi R. Neurogenesis in the hippocampal dentate gyrus of a Down syndrome model can be restored by neonatal treatment with an agonist of the BDNF TrkB receptor. ECNP 2016;26:S650-1.

12. Satgé $D$, Monteil $P$, Sasco $A$, Vital $A$, Ohgaki $H_{1}$ Geneix $A$, et al. Aspects of intracranial and spinal tumors in patients with Down syndrome and report of a rapidly progressing Grade 2 astrocytoma. Cancer 2001;91:1458-66.

13. Crome L, Valerie C, Slater E. A statistical note on cerebellar and brainstem weight in mongolism. J Intellect Disabil Res 1966;10:69-72.

14. Zellweger H. Down syndrome. In: Vinken PJ, Bruyn GW, eds. Handbook of clinical neurology. Amsterdam: North Holland Publishing, 1977;367-469.

15. Rotmensch S, Luo JS, Nores JA, Dimaio MS, Hobbins JC. Bilateral choroid plexus cysts in trisomy 21. Am J Obstet Gynecol 1992;166:591-2.

16. Geary M, Patel $\mathrm{S}$, Lamont R. Isolated choroid plexus cysts and association with fetal aneuploidy in an unselected population. Ultrasound Obstet Gynecol 1997;10:171-3.

17. Goel A, Weerakkody Y. Choroid plexus cyst (antenatal) [Internet]. Mel- bourne, AU: Radiopaedia, 2017 [cited 2017 Jul 1]. [https://radiopaedia. org/articles/choroid-plexus-cyst-antenatal-1]

18. Alami B, Youssef ALM, Addou O, Jaffal M, Sqali N, Boubou M, et al. Spectrum of benign intracranial cystic lesions [Internet]. Wien: European Society of Radiology, 2012 [cited 2017 Jul 1]. [http:// posterng.netkey.at/esr/viewing/index.php? $\operatorname{module=viewing}$ poster\&toi=10.1594/ecr2012/C-1945]

19. Osborn AG. Neuroglial cyst. In: Osborn AG, ed. Diagnostic imaging: brain. Salt Lake City, Utah: Amirsys, 2004;7-20.

20. Hassan J, Sepulveda W, Teixeira J, Cox PM. Glioependymal and arachnoid cysts: unusual causes of early ventriculomegaly in utero. Prenat Diagn 1996;16:729-33.

21. Ismail A, Tampieri D, Melanson D, Pokrupa R, Villemure JG, Bertrand G. Glioependymal cysts: CT and MR findings. J Comput Assist Tomogr 1992;16:860-4.

22. Osborn AG. Diagnostic neuroradiology. St. Louis: Mosby-Year Book, Inc.,1994. p. 626-65.

23. Frazier J, Garonzik I, Tihan T, Olivi A. Recurrent glioependymal cyst of the posterior fossa: an unusual entity containing mixed glial elements. Case report. J Neurooncol 2004;68:13-7.

24. Park K, Jung HW, Cho BK, Sim BS, Chi JG. Glioependymal cyst: a case report. J Korean Neurosurg Soc 1984;13:301-4.

25. Barth PG. Ependymal cysts [Internet]. San Diego, CA: Medlink neurology; 1999 Mar 23 [updated 2016 Jul 4; cited 2017 Jul 1] [http://www. medlink.com/article/ependymal_cysts\#Park_2012]

26. Eyselbergs M, Vanhoenacker FM, De Cuyper K, Kools D. Epileptic seizure due to neuroglial cyst. JBR-BTR 2012;95:142-3.

27. Zheng SP, Ju Y, You C. Glioependymal cyst in children: a case report. Clin Neurol Neurosurg 2013;115:2288-90. 